\title{
Chest Ultrasound versus Chest X-Ray in Children with Lower Respiratory Tract Infections
}

\author{
Elham Saad Ellithey Elkhazragy ${ }^{*}$, Saneya Abdel halim Fahmy', \\ Mona Sayed Mohammad Attaya ${ }^{2}$, Ashraf Mohammad Abd Elrahman ${ }^{3}$ \\ ${ }^{1}$ Pediatrics Department, Shoprahor Central Hospital, Ministry of Health, El-Senbellawein, Egypt \\ ${ }^{2}$ Pediatrics Department, Faculty of Medicine for Girls, Al-Azhar University, Cairo, Egypt \\ ${ }^{3}$ Diagnostic Radiology Department, Faculty of Medicine, Mansoura University, Mansoura, Egypt \\ Email: *ellham6112014@gmail.com
}

How to cite this paper: Elkhazragy, E.S.E., Fahmy, S.A.H., Attaya, M.S.M. and Elrahman, A.M.A. (2021) Chest Ultrasound versus Chest X-Ray in Children with Lower Respiratory Tract Infections. Open Journal of Pediatrics, 11, 597-607.

https://doi.org/10.4236/ojped.2021.114055

Received: September 11, 2021

Accepted: October 30, 2021

Published: November 2, 2021

Copyright $\odot 2021$ by author(s) and Scientific Research Publishing Inc. This work is licensed under the Creative Commons Attribution International License (CC BY 4.0).

http://creativecommons.org/licenses/by/4.0/

\section{(c) (i) Open Access}

\begin{abstract}
Background: Lower respiratory tract infections (LRTIs) are among the leading causes of morbidity and mortality among children during early childhood. Lung ultrasound is a relatively simple bedside method helping early diagnosis of these conditions. Purpose: To compare the findings of chest $\mathrm{X}$-ray (CXR) and of lung ultrasound (LUS) among children with lower respiratory tract infections. Subjects and Methods: A comparative cross-sectional study that included 100 children aged 6 months to 6 years with lower respiratory tract infections and 100 healthy age- and sex-matched children (controls). Included children were recruited from Mansoura University children hospital during the period from September 2020 to June 2021. Detailed findings of chest X-ray and lung ultrasound were compared. Results: Among 100 patients with LRTIs, the diagnosis of pneumonia, bronchiolitis and bronchitis were reported in $41 \%, 36 \%$ and $23 \%$ of cases respectively. Lung ultrasound was more sensitive than chest X-ray for diagnosing pneumonia $(97.6 \%$ for LUS vs. $92.7 \%$ for CXR) and bronchiolitis (91.7\% for LUS vs. $77.8 \%$ for CXR). Conclusion: Lung ultrasound is a sensitive tool for the assessment of lower respiratory tract infections. Further steps for application and validation are recommended.
\end{abstract}

\section{Keywords}

Lung, Ultrasound, Radiology, X-Ray, Pneumonia, Respiratory Infection

\section{Introduction}

Lower respiratory tract infections are one of the leading causes of global mor- 
bidity and mortality, especially among children under 5 years of age [1]. LRTIs are the second most common cause of mortality among children in Egypt [2]. Lower respiratory tract infections (bronchitis, bronchiolitis and pneumonia) are the cause of a considerable number of pediatric emergency room visits [3].

Imaging plays an important role in the detection, diagnosis and evaluation of a wide range of respiratory diseases [4]. Pediatric radiology is a complex issue. A wide variety of imaging modalities are used to help making an accurate and timely diagnosis, thus enabling rapid treatment of the many different disease entities found in the pediatric chest [5] [6].

Plain CXR remains the basis for chest assessment in childhood. It still plays a central role in the diagnosis of respiratory disease [7]. However, plain chest radiograph had several limitations; interpretation varies significantly among observers, it might result in unnecessary exposure of children to ionizing radiations, increased medical costs, time spent, and potential complications due to unnecessary medicine prescription [8] [9].

With the aim of avoiding excessive exposure of the children to radiation and to overwhelm the previous obstacles, the performance of alternate (non-ionizing) techniques has to be investigated [10]. Chest ultrasound is an appealing alternative as it is lacking ionizing radiation, is rapid to achieve, can be repeated without difficulty and can be performed and explained by pediatricians [11]. Furthermore, the new ultrasound machines are smaller in size and portable, making bedside ultrasound testing possible. In addition, ultrasound is cheaper and more easily available than CT and MRI, particularly in resource-limited countries [12].

Recent publications indicate that ultrasound plays a promising role in bedside lung parenchymal assessment, which suggests that it can replace chest radiographs [3].

\section{Aim of the Work}

Because LRTIs are very common, specifically in the pediatric age group, it is essential to find a bedside diagnostic tool able to achieve and ultimately overcome the efficacy of CXR in the diagnosis of these diseases, so the present study was conducted to compare between the findings of chest X-ray and those of chest ultrasound among children with lower respiratory tract infections.

\section{Subjects and Methods}

This study is a case control study included 100 children aged 6 month to 6 years with lower respiratory tract infections and 100 healthy age- and sex-matched children (controls). Included children were recruited from Mansoura University children hospital during the period from September 2020 to June 2021. Children presented with symptoms and signs suggestive of lower respiratory tract infection including: respiratory distress (tachypnea, subcostal, intercostal retractions, grunting or cyanosis), acute wheezes, prolonged fever, abnormal auscultatory findings (wheezes, crepitations/crackles, differential breath sounds), or persis- 
tent cough. Patients with chronic lung diseases, hemodynamic instability, severe neuromuscular disease, suspected congenital or acquired immunodeficiency or with known congenital heart diseases were excluded.

The clinical diagnosis of bronchiolitis was done according to the guidelines of the American Academy of Pediatrics as a set of clinical signs and symptoms that occur in children under 2 years of age, including viral prodromal symptoms of the upper respiratory tract followed by increased breathing effort and wheezing [13]. Pneumonia was diagnosed when there is fever $>38.5^{\circ} \mathrm{C}$ together with chest indrawing and a high respiratory rate [14]. Acute bronchitis was diagnosed when there is cough, associated with different degrees of moist rales in both lungs, or wheezing without evidence of pneumonia [15].

Radiological examination: Chest X-rays was performed in frontal view, either in the antero-posterior lie down or in the postero-anterior upright view, according to the age of the patient. Lateral radiographs were not routinely performed to avoid unnecessary exposure to further radiation [16]. The following chest X-ray abnormalities were reported [9]:

- Pleural effusion and pneumothorax.

- Interstitial infiltrates or increased interstitial markings.

- Lung hyperexpansion.

- Inflammatory infiltrate: include consolidation pneumonia or non-interstitial infiltrates.

Sonographic examination: Chest ultrasound was done using SonoScape machine (SonoScape SSI-8000 Guangdong, China). For performing of the chest ultrasound, the chest is divided into three areas: front, back and sides. Each area is scanned in the vertical and horizontal planes, up and down and inward, respectively [10]. Ultrasound findings were classified according to the following findings [17]:

- Small subpleural consolidations $<10 \mathrm{~mm}$ in diameter.

- Consolidations $>10 \mathrm{~mm}$ in diameter may be associated with air bronchogram: usually associated with pneumonia.

- Interstitial syndrome -B7 lines: increased B lines, the supposed B7 lines are around $7 \mathrm{~mm}$ separately and usually $<7 \mathrm{~mm}$.

- Alveolar-interstitial syndrome -B3 lines: characterized by numerous B lines at a space of around $3 \mathrm{~mm}$. They denote the existence of fluid in the alveoli.

Ethical considerations: The study protocol was introduced, reviewed and accepted by the institutional review board (IRB) of Faculty of Medicine for girls. The study procedures were completed according to research ethics of declaration of Helsinki.

Statistical Analysis: All analyses were completed by the Statistical Package for Social Science (SPSS) version 23 for windows (IBM-SPSS Inc, Chicago, IL, USA). Student " $t$ " test, or Mann Whitney " $U$ " tests were used to analyze quantitative data; while Chi square or Fisher exact tests were used to analyze qualitative data. $\mathrm{P}$-value $<0.05$ was considered statistically significant. 


\section{Results}

Among the 100 patients with LRTI, 41 patients had pneumonia, 36\% had bronchiolitis and $23 \%$ had bronchitis. The mean age of children in the case group was $34.2 \pm 11.5$ months; most of studied children were males (58\%) and rural residents (72\%). Vital data and laboratory investigations of the studied cases were shown in Table 1. Regarding clinical presentations, cough was the most frequent symptom (100\%), followed by nasal discharge (97\%) and fever (92\%). Respiratory distress was reported in 65\% of children (Table 2). Regarding CXR findings, the

Table 1. Demographic, vital data and laboratory findings among the study groups.

\begin{tabular}{ccccc}
\hline & $\begin{array}{c}\text { Case group } \\
(\mathbf{n}=100)\end{array}$ & $\begin{array}{c}\text { Control group } \\
(\mathbf{n}=100)\end{array}$ & Test & P \\
\hline Age (months) & $34.2 \pm 11.5$ & $36.1 \pm 13.4$ & 1.07 & 0.28 \\
Males & $58(58 \%)$ & $53(53 \%)$ & 0.51 & 0.47 \\
Females & $42(42 \%)$ & $47(47 \%)$ & & \\
Residence $\quad$ Rural & $72(72 \%)$ & $66(66 \%)$ & 0.84 & 0.36 \\
Urban & $28(28 \%)$ & $34(34 \%)$ & & \\
Temperature $\left({ }^{\circ} \mathrm{C}\right)$ & $38.12 \pm 0.67$ & $37.1 \pm 0.22$ & 14.5 & $<0.001^{*}$ \\
Heart rate (beat/min) & $123.6 \pm 18.3$ & $107.4 \pm 12.5$ & 7.3 & $<0.001^{*}$ \\
Respiratory rate (cycle/min) & $43.65 \pm 13.8$ & $27.89 \pm 4.66$ & 10.8 & $<0.001^{*}$ \\
Total leukocytes & $11.71 \pm 2.40$ & $7.45 \pm 2.02$ & 13.5 & $<0.001^{*}$ \\
Neutrophils count & $6.35 \pm 2.51$ & $4.83 \pm 1.23$ & 5.43 & $<0.001^{*}$ \\
Lymphocytes count & $4.87 \pm 1.25$ & $3.12 \pm 1.47$ & 4.34 & $<0.001^{*}$ \\
C-reactive protein & $12(4.5-18)$ & $2(1-3)$ & 11.1 & $<0.001^{*}$ \\
\hline
\end{tabular}

*: Significant.

Table 2. Clinical presentations of the case group.

\begin{tabular}{cc}
\hline Symptom* & Value \\
\hline Nasal discharge (n, \%) & $97(97 \%)$ \\
Cough (n, \%) & $100(100 \%)$ \\
Persistent cough (>2 weeks) (n, \%) & $11(11 \%)$ \\
Fever (n, \%) & $92(92 \%)$ \\
Wheezes (n, \%) & $46(46 \%)$ \\
Respiratory distress (n, \%) & $65(65 \%)$ \\
Decreased air entry (n, \%) & $74(74 \%)$ \\
Crackles & $52(52 \%)$ \\
Prolonged expiration & $52(52 \%)$ \\
Rheezes (small) & $47(47 \%)$ \\
Bronchi (large) & $42(42 \%)$ \\
\hline
\end{tabular}


most frequent finding among patients with pneumonia was consolidation (68\%), followed by interstitial infiltrates (20\%), while interstitial infiltrates and lung hyper-expansion were the main findings in bronchiolitis (50\% and $20 \%$ respectively), while the majority of children (82.5\%) with acute bronchitis had normal chest X-ray (Table 3). As for LUS, the most frequent finding among patients with pneumonia was consolidation (75\%), followed by numerous B3 lines and pleural effusion (10\%). The main findings in bronchiolitis were numerous B3 lines (39\%) and increase B7 lines (interstitial syndrome; $25 \%$ ), while the majority of children with acute bronchitis (78\%) had normal ultrasound findings (Table 4). Diagnostic performances of CXR and LUS were shown in Table 5. Lung ultrasound was more sensitive than chest X-ray for diagnosing pneumonia $(97.6 \%$ for LUS vs. $92.7 \%$ for CXR) and bronchiolitis (91.7\%\% for LUS vs. $77.8 \%$ for CXR).

Table 3. Chest X-ray findings in relation to clinical diagnosis.

\begin{tabular}{ccccc}
\hline & $\begin{array}{c}\text { Pneumonia } \\
(\mathbf{n}=41)\end{array}$ & $\begin{array}{c}\text { Bronchiolitis } \\
(\mathbf{n = 3 6})\end{array}$ & $\begin{array}{c}\text { Bronchitis } \\
(\mathbf{n}=\mathbf{2 3})\end{array}$ & Total \\
\hline Consolidation, non-interstitial infiltrates & $28(68 \%)$ & $3(8.5 \%)$ & $0(0 \%)$ & 31 \\
Increased interstitial markings & $8(19.5 \%)$ & $18(50 \%)$ & $2(8.5 \%)$ & 28 \\
Lung hyper-expansion & $0(0 \%)$ & $7(19.5 \%)$ & $2(8.5 \%)$ & 9 \\
Pleural effusion & $2(5 \%)$ & $0(0 \%)$ & $0(0 \%)$ & 2 \\
Negative chest radiography & $3(7.5 \%)$ & $8(22 \%)$ & $19(82.5 \%)$ & 30 \\
\hline
\end{tabular}

Table 4. Lung ultrasound findings in relation to clinical diagnosis.

\begin{tabular}{ccccc}
\hline & $\begin{array}{c}\text { Pneumonia } \\
(\mathbf{n}=\mathbf{4 1})\end{array}$ & $\begin{array}{c}\text { Bronchiolitis } \\
(\mathbf{n}=\mathbf{3 6})\end{array}$ & $\begin{array}{c}\text { Bronchitis } \\
(\mathbf{n}=\mathbf{2 3})\end{array}$ & Total \\
\hline Consolidations > 10 mm & $28(68 \%)$ & $1(3 \%)$ & $0(0 \%)$ & 29 \\
Sub-pleural consolidations & $3(7.5 \%)$ & $8(22 \%)$ & $2(8.5 \%)$ & 13 \\
Numerous B3 lines & $4(10 \%)$ & $14(39 \%)$ & $0(0 \%)$ & 18 \\
Numerous B7 lines & $1(2.5 \%)$ & $9(25 \%)$ & $3(13 \%)$ & 13 \\
Pleural effusion & $4(10 \%)$ & $1(3 \%)$ & $0(0 \%)$ & 5 \\
Negative lung ultrasound & $1(2.5 \%)$ & $3(8 \%)$ & $18(78 \%)$ & 22 \\
\hline
\end{tabular}

Table 5. Diagnostic performance of chest X-ray and ultrasound in pneumonia and bronchiolitis.

\begin{tabular}{cccccc}
\hline & & Sensitivity & Specificity & PPV & NPV \\
\hline \multirow{2}{*}{ Chest X-ray } & Pneumonia & $92.7 \%$ & $95.6 \%$ & $84.4 \%$ & $98.1 \%$ \\
& Bronchiolitis & $77.8 \%$ & $89.7 \%$ & $66.7 \%$ & $93.8 \%$ \\
\hline \multirow{2}{*}{ Chest ultrasound } & Pneumonia & $97.6 \%$ & $95.9 \%$ & $88.9 \%$ & $99.1 \%$ \\
& Bronchiolitis & $91.7 \%$ & $95.9 \%$ & $86.8 \%$ & $97.5 \%$ \\
\hline
\end{tabular}




\section{Discussion}

Diagnosis of respiratory tract infections is centered mainly on clinical assessment; however, imaging studies are required in some cases. Lung ultrasound has exceptional advantages: it can perform bedside examinations, avoid radiation exposure, shorten the patient's stay in the emergency room, can be repeated inexpensively during follow-up care and can be used without problems in resource-poor environments [18].

Regarding lung ultrasound findings among the case group, we found that the most frequent finding was consolidation (42\%) followed by numerous B lines (31\%). Negative ultrasound findings were observed in $22 \%$ of cases.

Among studies that evaluated lung ultrasound in relation to LRTIs, there is a great heterogeneity found across individual studies and a reliable reference standard is absent, which make a longitudinal comparison between different studies very difficult. For example, Buonsenso et al. [19] reported that consolidation was found among $91 \%$ of cases with acute LRTIs, while vertical deep artifacts (numerous B lines) was reported among $72 \%$ of cases, and pleural effusion among $28 \%$ of cases. However, they did not differentiate between B3 and B7 lines.

Another study by Ellington et al. [20] observed normal ultrasound findings among $36.5 \%$ of children presented with LRTIs, large consolidation was present in $16.5 \%$, small consolidations among $33 \%$. They did not comment on the frequency of B3 line, and had different methodological assessment regarding interstitial syndromes.

Ultrasound is respected a maintainable type of technology for developing countries, due to its relatively low cost, low maintenance and supply costs, portability, and stability compared to other imaging modalities [21]. In addition to its well-known benefits, ultrasound (especially LUS) can be easily learned by various healthcare professionals (not just radiology) for quick assessment and treatment in various settings. Ultrasound machines can be used by a single operator, handheld device, and can provide diagnostic capabilities at a much lower cost than other imaging tools such as CT or magnetic resonance imaging (MRI) and are used in rural areas in low and mid-income Countries (LMIC), compared to traditional radiology [22]. These properties make ultrasound an attractive option for clinical applications of developing countries for inpatient and outpatient use.

Regarding the radiological and sonographic findings among children with pneumonia, consolidation was the most frequent finding in both CXR and LUS. Furthermore, the sensitivity of consolidation and overall positive findings on LUS was more than CXR.

LUS is consistently used to diagnose pediatric pneumonia. Positive results for pneumonia include these findings: lung consolidation, abnormalities of the pleural line (increased thickness or irregularity), zones with sparse or confluent B-lines, and pleural effusion [8].

Several studies had confirmed the role of LUS among children with pneumo- 
nia. Claes et al. [10] studied the performance of chest ultrasound in pediatric pneumonia. Ultrasound detected at least one area of consolidation in $98 \%$ of patients with positive X-rays. Ultrasound identified $91 \%$ of consolidations on X-ray. Yadav et al. [23] found that LUS has high sensitivity (98.02\%), specificity (64.71\%), PPV (94.29) and NPV (84.62) for diagnosing radiologically proven CAP.

In contrast, Ellington et al. [20] observed normal ultrasound findings among $79 \%$ of cases with pneumonia. However, in their findings they did not included B3 lines (alveolar-interstitial syndrome) as abnormal finding that may explain the low sensitivity.

In the study conducted by Biagi et al. [24], CXR was positive for parenchymal consolidation consistent with pneumonia in $98 \%$ cases. CXR showed a sensitivity of $96 \%$ and specificity of $87.1 \%$ in identifying children with bronchiolitis affected by a concurrent bacterial pneumonia, with a PPV of $75 \%$ and a NPV of $98.2 \%$. LUS had a sensitivity of $100 \%$ and a specificity of $83.9 \%$; the PPV and NNV were $71.4 \%$ and $100 \%$ respectively.

Among children with community-acquired pneumonia (CAP), Berce et al. [25] pneumonic infiltrates were detected on CXR in $76.7 \%$ of them, while LUS detected multiple consolidations in $40.8 \%$ and bilateral consolidations in $28.6 \%$ of them.

Bloise et al. [26] compared LUS to chest X-ray for the diagnosis of CAP in children. Chest X-ray found unilateral consolidations in $75.6 \%$ of patients and bilateral consolidations in $25 \%$. Overall, LUS was able to confirm the diagnosis of CAP in $97.5 \%$ of patients, showing the presence of single or multiple areas of consolidation. LUS showed a sensitivity of $97 \%$ and a specificity of $96 \%$.

A performed meta-analysis confirmed high sensitivity (96\%) and specificity (93\%) of LUS for detecting pneumonia in children [27]. The accuracy of LUS for the diagnosis of pneumonia has been confirmed worldwide, and there is international agreement on this, including during the COVID-19 pandemic [28] [29].

A more recent systematic review and meta-analysis included 17 study and 2612 pooled cases found the sensitivity and specificity of LUS $94 \%$ and $93 \%$ respectively. However, no agreement on reference standard was detected: nine studies used chest X-rays, while four studies considered the clinical diagnosis [30].

Regarding the radiological and sonographic findings among children with bronchiolitis, interstitial infiltrates was the most frequent finding in CXR, while numerous B lines was the main findings in LUS. Furthermore, the overall sensitivity of LUS was more than CXR.

LUS findings have been described for acute viral bronchiolitis. LU signs in bronchiolitis are non-homogenous lungs with pleural line abnormalities (pleural line thickening and/or irregularities, smaller "subpleural" consolidations), areas with multiple B-lines, and larger consolidations [31].

Varshney et al. [32] enrolled 94 children with respiratory tract infections and wheeze. LUS was positive in $42 \%$ of patients (multiple B-lines was reported in 
$80 \%$, consolidation in $64 \%$ and pleural abnormalities in $23 \%$ ). Jaszczołt et al. [9] compared diagnostic imaging findings in children with bronchiolitis. Chest X-ray showed lesions in only $19 \%$ of cases, whereas ultrasound abnormalities were found in $100 \%$ of patients. Supino et al. [33] studied point-of-care lung ultrasound in infants with bronchiolitis in the pediatric emergency department. The main findings on LUS examination were confluent lines B and subpleural consolidation.

These findings, together with evidence from previous studies, will certainly provide a solid foundation for the introduction of LUS in the guidelines for the diagnosis and treatment of children's respiratory tract infections in the future.

Our study has limitations to consider. The chest CT scan gold is the standard for diagnosing ALRTI; but the CT has not been carried out in this work because its routine use is not ethical in children. Thus, ALRTI diagnosis for patients' inclusion in the present study was made on a clinical basis following the available guidelines. Thus, the stratification of patients according to the clinical diagnosis cannot be $100 \%$ accurate. Moreover, the timing of ultrasound performance was not the same across all the patients. Thus, we cannot recommend the optimal timing as an indication in the application of LUS.

\section{Conclusion}

In general, lung ultrasound was more sensitive and specific than chest X-ray for the diagnosis of both pneumonia and bronchiolitis. In contrast to chest X-ray, lung ultrasound had more diversity of positive findings and can detect some subtle findings presented as small consolidations and numerous B lines. Lung ultrasound is used as an alternate or supportive for chest X-ray in the diagnosis of pneumonia and bronchiolitis.

\section{Conflicts of Interest}

The authors declare no conflicts of interest regarding the publication of this paper.

\section{References}

[1] Korsun, N., Angelova, S., Trifonova, I., Georgieva, I., Voleva, S., Tzotcheva, I., Mileva, S., Ivanov, I., Tcherveniakova, T. and Perenovska, P. (2019) Viral Pathogens Associated with Acute Lower Respiratory Tract Infections in Children Younger than 5 Years of Age in Bulgaria. Brazilian Journal of Microbiology, 50, 117-125. https://doi.org/10.1007/s42770-018-0033-2

[2] GBD 2017 Child and Adolescent Health Collaborators (2019) Diseases, Injuries, and Risk Factors in Child and Adolescent Health, 1990 to 2017: Findings from the Global Burden of Diseases, Injuries, and Risk Factors 2017 Study. JAMA Pediatrics, 173, e190337. https://doi.org/10.1001/jamapediatrics.2019.0337

[3] Poutanen, R., Virta, T., Heikkilä, P., Pauniaho, S. L., Csonka, P., Korppi, M., Renko, M. and Palmu, S. (2021) National Current Care Guidelines for Paediatric Lower Respiratory Tract Infections Reduced the Use of Chest Radiographs but Local Variations Were Observed. Acta Paediatrica, 110, 1594-1600. 
https://doi.org/10.1111/apa.15692

[4] Dong, D., Tang, Z., Wang, S., Hui, H., Gong, L., Lu, Y., Xue, Z., Liao, H., Chen, F., Yang, F., Jin, R., Wang, K., Liu, Z., Wei, J., Mu, W., Zhang, H., Jiang, J., Tian, J. and Li, H. (2021) The Role of Imaging in the Detection and Management of COVID-19: A Review. IEEE Reviews in Biomedical Engineering, 14, 16-29. https://doi.org/10.1109/RBME.2020.2990959

[5] Lovrenski, J. (2020) Pediatric Lung Ultrasound-Pros and Potentials. Pediatric Radiology, 50, 306-313. https://doi.org/10.1007/s00247-019-04525-y

[6] Kermany, D.S., Goldbaum, M., Cai, W., Valentim, C., Liang, H., Baxter, S.L., McKeown, A., Yang, G., Wu, X., Yan, F., Dong, J., Prasadha, M.K., Pei, J., Ting, M., Zhu, J., Li, C., Hewett, S., Dong, J., Ziyar, I., Shi, A., et al. (2018) Identifying Medical Diagnoses and Treatable Diseases by Image-Based Deep Learning. Cell, 172, 1122-1131. https://doi.org/10.1016/j.cell.2018.02.010

[7] Karimi, E. (2019) Comparing Sensitivity of Ultrasonography and Plain Chest Radiography in Detection of Pneumonia: A Diagnostic Value Study. Archives of Academic Emergency Medicine, 7, e8.

[8] Jaworska, J., Komorowska-Piotrowska, A., Pomiećko, A., Wiśniewski, J., Woźniak, M., Littwin, B., Kryger, M., Kwaśniewicz, P., Szczyrski, J., Kulińska-Szukalska, K., Buda, N., Doniec, Z. and Kosiak, W. (2020) Consensus on the Application of Lung Ultrasound in Pneumonia and Bronchiolitis in Children. Diagnostics, 10, Article ID: 935. https://doi.org/10.3390/diagnostics10110935

[9] Jaszczołt, S., Polewczyk, T., Dołęga-Kozierowska, M., Woźniak, M. and Doniec, Z. (2018) Comparison of Lung Ultrasound and Chest X-Ray Findings in Children with Bronchiolitis. Journal of Ultrasonography, 18, 193-197. https://doi.org/10.15557/JoU.2018.0029

[10] Claes, A.S., Clapuyt, P., Menten, R., Michoux, N. and Dumitriu, D. (2017) Performance of Chest Ultrasound in Pediatric Pneumonia. European Journal of Radiology, 88, 82-87. https://doi.org/10.1016/j.ejrad.2016.12.032

[11] Karkar, A.M., Zannoun, M.A., Eldeek, A.M.F. and Sakr, M.M.A. (2021) A Comparison between the Use of Chest X-Ray and Lung Ultrasound in the Diagnosis of Pneumonia in Children in Damietta Governorate. International Journal of Medical Arts, 3, 938-945. https://doi.org/10.21608/IJMA.2020.36693.1154

[12] Heuvelings, C.C., Bélard, S., Familusi, M.A., Spijker, R., Grobusch, M.P. and Zar, H.J. (2019) Chest Ultrasound for the Diagnosis of Paediatric Pulmonary Diseases: A Systematic Review and Meta-Analysis of Diagnostic Test Accuracy. British Medical Bulletin, 129, 35-51. https://doi.org/10.1093/bmb/ldy041

[13] Ralston, S.L., Lieberthal, A.S., Meissner, H.C., Alverson, B.K., Baley, J.E., Gadomski, A.M., Johnson, D.W., Light, M.J., Maraqa, N.F., Mendonca, E.A., Phelan, K.J., Zorc, J.J., Stanko-Lopp, D., Brown, M.A., Nathanson, I., Rosenblum, E., Sayles, S., Hernandez-Cancio, S. and American Academy of Pediatrics (2014) Clinical Practice Guideline: The Diagnosis, Management, and Prevention of Bronchiolitis. Pediatrics, 134, e1474-e1502. https://doi.org/10.1542/peds.2014-2742

[14] Harris, M., Clark, J., Coote, N., Fletcher, P., Harnden, A., McKean, M., Thomson, A. and British Thoracic Society Standards of Care Committee (2011) British Thoracic Society Guidelines for the Management of Community Acquired Pneumonia in Children: Update 2011. Thorax, 66, ii1-ii23.

https://doi.org/10.1136/thoraxjnl-2011-200598

[15] Kinkade, S. and Long, N.A. (2016) Acute Bronchitis. American Family Physician, 94, 560-565. 
[16] Zar, H.J., Moore, D.P., Andronikou, S., Argent, A.C., Avenant, T., Cohen, C., Green, R.J., Itzikowitz, G., Jeena, P., Masekela, R., Nicol, M.P., Pillay, A., Reubenson, G. and Madhi, S.A. (2020) Diagnosis and Management of Community-Acquired Pneumonia in Children: South African Thoracic Society Guidelines. African Journal of Thoracic and Critical Care Medicine, 26, 98-116. https://doi.org/10.7196/AJTCCM.2020.v26i3.104

[17] Basile, V., Di Mauro, A., Scalini, E., Comes, P., Lofù, I., Mostert, M., Tafuri, S. and Manzionna, M.M. (2015) Lung Ultrasound: A Useful Tool in Diagnosis and Management of Bronchiolitis. BMC Pediatrics, 15, Article No. 63. https://doi.org/10.1186/s12887-015-0380-1

[18] Allinovi, M., Parise, A., Giacalone, M., Amerio, A., Delsante, M., Odone, A., Franci, A., Gigliotti, F., Amadasi, S., Delmonte, D., Parri, N. and Mangia, A. (2020) Lung Ultrasound May Support Diagnosis and Monitoring of COVID-19 Pneumonia. UItrasound in Medicine \& Biology, 46, 2908-2917. https://doi.org/10.1016/j.ultrasmedbio.2020.07.018

[19] Buonsenso, D., Musolino, A., Ferro, V., De Rose, C., Morello, R., Ventola, C., Liotti, F.M., De Sanctis, R., Chiaretti, A., Biasucci, D.G., Spanu, T., Sanguinetti, M. and Valentini, P. (2021) Role of Lung Ultrasound for the Etiological Diagnosis of Acute Lower Respiratory Tract Infection (ALRTI) in Children: A Prospective Study. Journal of Ultrasound, 1-13. https://doi.org/10.1007/s40477-021-00600-Z

[20] Ellington, L.E., Gilman, R.H., Chavez, M.A., Pervaiz, F., Marin-Concha, J., Compen-Chang, P., Riedel, S., Rodriguez, S.J., Gaydos, C., Hardick, J., Tielsch, J.M., Steinhoff, M., Benson, J., May, E.A., Figueroa-Quintanilla, D., Checkley, W. and Lung Ultrasound for Pneumonia Assessment (LUPA) Study Investigators (2017) Lung Ultrasound as a Diagnostic Tool for Radiographically-Confirmed Pneumonia in Low Resource Settings. Respiratory Medicine, 128, 57-64. https://doi.org/10.1016/j.rmed.2017.05.007

[21] Buonsenso, D. and De Rose, C. (2021) Implementation of Lung Ultrasound in Lowto Middle-Income Countries: A New Challenge Global Health? European Journal of Pediatrics, 1-8. https://doi.org/10.1007/s00431-021-04179-9

[22] Stewart, K.A., Navarro, S.M., Kambala, S., Tan, G., Poondla, R., Lederman, S., Barbour, K. and Lavy, C. (2020) Trends in Ultrasound Use in Low and Middle Income Countries: A Systematic Review. International Journal of MCH and AIDS, 9, 103-120.

[23] Yadav, K.K., Awasthi, S. and Parihar, A. (2017) Lung Ultrasound Is Comparable with Chest Roentgenogram for Diagnosis of Community-Acquired Pneumonia in Hospitalised Children. The Indian Journal of Pediatrics, 84, 499-504. https://doi.org/10.1007/s12098-017-2333-1

[24] Biagi, C., Pierantoni, L., Baldazzi, M., Greco, L., Dormi, A., Dondi, A., Faldella, G. and Lanari, M. (2018) Lung Ultrasound for the Diagnosis of Pneumonia in Children with Acute Bronchiolitis. BMC Pulmonary Medicine, 18, Article No. 191. https://doi.org/10.1186/s12890-018-0750-1

[25] Berce, V., Tomazin, M., Gorenjak, M., Berce, T. and Lovrenčič, B. (2019) The Usefulness of Lung Ultrasound for the Aetiological Diagnosis of Community-Acquired Pneumonia in Children. Scientific Reports, 9, Article No. 17957. https://doi.org/10.1038/s41598-019-54499-y

[26] Bloise, S., La Regina, D.P., Pepino, D., Iovine, E., Laudisa, M., Di Mattia, G., Nicolai, A., Nenna, R., Petrarca, L., Mancino, E., Frassanito, A. and Midulla, F. (2021) Lung Ultrasound Compared to Chest X-Ray for the Diagnosis of CAP in Children. Pediatrics International, 63, 448-453. https://doi.org/10.1111/ped.14469

[27] Pereda, M.A., Chavez, M.A., Hooper-Miele, C.C., Gilman, R.H., Steinhoff, M.C., El- 
lington, L.E., Gross, M., Price, C., Tielsch, J.M. and Checkley, W. (2015) Lung Ultrasound for the Diagnosis of Pneumonia in Children: A Meta-Analysis. Pediatrics, 135, 714-722. https://doi.org/10.1542/peds.2014-2833

[28] Volpicelli, G. and Gargani, L. (2020) Sonographic Signs and Patterns of COVID-19 Pneumonia. The Ultrasound Journal, 12, Article No. 22. https://doi.org/10.1186/s13089-020-00171-w

[29] Buonsenso, D., Parri, N., De Rose, C., Valentini, P. and Gemelli-Pediatric COVID-19 Team (2021) Toward a Clinically Based Classification of Disease Severity for Paediatric COVID-19. The Lancet: Infectious Diseases, 21, 22. https://doi.org/10.1016/S1473-3099(20)30396-0

[30] Orso, D., Ban, A. and Guglielmo, N. (2018) Lung Ultrasound in Diagnosing Pneumonia in Childhood: A Systematic Review and Meta-Analysis. Journal of Ultrasound, 21, 183-195. https://doi.org/10.1007/s40477-018-0306-5

[31] Yousef, N. and De Luca, D. (2018) The Role of Lung Ultrasound in Viral Lower Respiratory Tract Infections. American Journal of Perinatology, 35, 527-529. https://doi.org/10.1055/s-0038-1637758

[32] Varshney, T., Mok, E., Shapiro, A.J., Li, P. and Dubrovsky, A.S. (2016) Point-of-Care Lung Ultrasound in Young Children with Respiratory Tract Infections and Wheeze. Emergency Medicine Journal, 33, 603-610. https://doi.org/10.1136/emermed-2015-205302

[33] Supino, M.C., Buonsenso, D., Scateni, S., Scialanga, B., Mesturino, M.A., Bock, C., Chiaretti, A., Giglioni, E., Reale, A. and Musolino, A.M. (2019) Point-of-Care Lung Ultrasound in Infants with Bronchiolitis in the Pediatric Emergency Department: A Prospective Study. European Journal of Pediatrics, 178, 623-632.

https://doi.org/10.1007/s00431-019-03335-6 